\title{
Organic Intercalation of Unsaturated Amines into Layered Polymer Crystals and Solid-State Photoreactivity of the Guest Molecules in Constrained Interlayers
}

\author{
Akikazu Matsumoto, ${ }^{*, * *, \dagger}$ Daisuke Fujioka, ${ }^{*}$ and Takafumi Kunisue* \\ *Department of Applied Chemistry, Graduate School of Engineering, Osaka City University, \\ Sugimoto, Sumiyoshi-ku, Osaka 558-8585, Japan \\ **PRESTO, Japan Science and Technology Corporation (JST)
}

(Received April 11, 2003; Accepted May 20, 2003)

\begin{abstract}
We have investigated the intercalation of several unsaturated amines using poly(muconic acid) crystals as the layered organic polymer host. Allyl- and oleylamines are intercalated into the polymer crystals in order to introduce an olefin moiety in the side chain of poly(muconic acid). The oleylammonium polymer crystals are alternatively obtained by the topochemical polymerization of oleylammonium muconate as the corresponding ammonium monomer crystals under photoirradiation in the crystalline state, while the photoirradiation of the allylammonium muconate crystals results in the formation of isomers. The inner double bond of the intercalated oleyl group has a low reactivity under UV irradiation, and the allyl group has no reactions. In contrast, diene and diyne moieties introduced into the side chain by the intercalation using 2,4-hexadienyl-, 2,4-tetradecyldienyl-, and 10,12-pentacosadiynylamines as the guest amines readily react to give a new type of the polymer crystal consisting of alternately stacked polymer nano-sheets. We have revealed that the intercalation of long-chain unsaturated amines proceeds in a high conversion, and the photoreactivity of the unsaturated functional groups in the side chain is determined by the kind of unsaturated groups and the stacking distance of the amine molecules in the layers.

KEY WORDS Layered Polymer Crystals / Intercalation / Poly(muconic acid) / Solid-State

Photoreaction / Polydiacetylene /
\end{abstract}

Organic/inorganic nano-composites with an organized structure have attracted interests in the fundamental and applied fields of polymer chemistry and nanomaterial science. ${ }^{1-3}$ A large number of inorganic solids with a two-dimensional structure such as clays, metal phosphonates or phosphites, graphite, and metal oxides have been reported, ${ }^{4,5}$ and the properties and functions of these layered materials are modified by combination with organic molecules as the guest compounds. ${ }^{6-11}$ The combination of materials with a different nature efficiently induces a new property and function, which cannot be attained from an organic or inorganic compound alone. The structure and properties of the composites consisting of various types of clays and polymers have also been investigated. ${ }^{12-15}$ In contrast to a large number of studies on intercalation systems made of inorganic compounds or inorganic-organic hybrids, very few examples are known as an intercalation system consisting of organic compounds as both the host and guest. ${ }^{16-21}$

We have previously demonstrated the fundamental features and mechanism of the intercalation of various alkylamines into poly(muconic acid) (PMA) as the organic host compound $d^{21-24}$ (Scheme 1). Long-chain alkylamines are suitable as the guest molecules and the intercalation provides a new layered polymer crystal with an interlayer spacing different from that of the

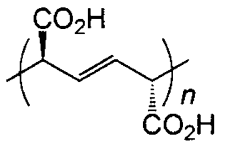

PMA crystals
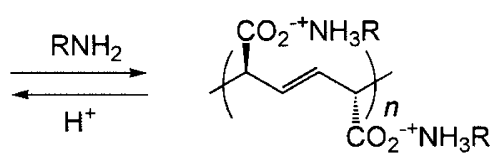

Scheme 1.

original PMA crystals. The organic intercalation system consisting of layered organic polymers and organic guest amines has some characteristics different from a large number of known intercalation compounds using the inorganic hosts. For example, carboxylic groups orderly arrange along the polymer chains in a high density in a stacking distance of $5 \AA$ in the polymer crystals as the organic intercalation host. ${ }^{23,25,26}$ This structural feature is potentially used as a new kind of intercalation material for reactions; namely, the interlayer space of the layered crystals may function as the specific reaction vessel to give a stereospecific reaction product due to a reactivity different from that in isotropic medium. Especially, photochemical properties are of great interests because photoactive species are immobilized and restricted in a constrained interlayer space when they are intercalated into organic polymer crystals as the host. ${ }^{27}$ In this paper, we describe the synthesis and photoreactivity of polymer crystals intercalated with unsaturated amines including olefin, diene, and diyne moi-

${ }^{\dagger}$ To whom correspondence should be addressed(Phone/Fax: +81-6-6605-2981, E-mail: matsumoto@a-chem.eng.osaka-cu.ac.jp). 
eties as a functional group (Scheme 2).

\section{EXPERIMENTAL}

\section{Materials}

$(Z, Z)$-Muconates were prepared by the reaction of $(Z, Z)$-muconic acid with the corresponding amine in methanol at room temperature and quantitatively isolated by precipitation with a large amount of diethyl ether, followed by recrystallization from methanol.

Allylammonium (Z,Z)-muconate $\mathbf{M - 1}$. Colorless needles $\left(\mathrm{CH}_{3} \mathrm{OH}\right) ; \mathrm{mp} 111{ }^{\circ} \mathrm{C}$ (decomp); ${ }^{1} \mathrm{HNMR}$ $\left(400 \mathrm{MHz}, \mathrm{CD}_{3} \mathrm{OD}\right) \delta 7.36\left(\mathrm{~m}, \mathrm{CH}=\mathrm{CHCO}_{2}, 2 \mathrm{H}\right), 5.79$ $\left(\mathrm{m}, \mathrm{CH}=\mathrm{CHCO}_{2}\right.$ and $\left.\mathrm{NCH}_{2} \underline{\mathrm{CH}}=\mathrm{CH}_{2}, 4 \mathrm{H}\right), 5.26(\mathrm{~m}$, $\left.\mathrm{NCH}_{2} \mathrm{CH}=\overline{\mathrm{C}}_{2}, 4 \mathrm{H}\right), 3.44\left(\mathrm{~m}, \mathrm{NC}_{2} \mathrm{CH}=\mathrm{CH}_{2}, 4 \mathrm{H}\right)$; IR $(\mathrm{KBr}) 1581\left(v_{\mathrm{C}=\mathrm{C}}\right), 1512\left(v_{\mathrm{C}=\mathrm{O}}\right), 939\left(\delta_{\mathrm{CH}=\mathrm{CH}}\right) \mathrm{cm}^{-1}$.

Oleylammonium (Z,Z)-muconate $\mathbf{M}-2$. Colorless powder $\left(\mathrm{CH}_{3} \mathrm{OH}\right) ; \mathrm{mp} 126{ }^{\circ} \mathrm{C}$ (decomp); ${ }^{1} \mathrm{HNMR}$ $\left(400 \mathrm{MHz}, \mathrm{CD}_{3} \mathrm{OD}\right) \delta 7.37\left(\mathrm{~m}, \mathrm{C} \underline{\mathrm{H}}=\mathrm{CHCO}_{2}, 2 \mathrm{H}\right)$, $5.90\left(\mathrm{~m}, \mathrm{CH}=\mathrm{CHCO}_{2}, 2 \mathrm{H}\right), 5.34\left(\mathrm{~m}, \overline{\mathrm{CH}}_{2} \mathrm{C} \underline{\mathrm{H}}=\mathrm{CHCH}_{2}\right.$, $4 \mathrm{H}), 2.88\left(\mathrm{t}, \bar{J}=7.5 \mathrm{~Hz}, \mathrm{NCH}_{2}, 4 \mathrm{H}\right), 2.03(\mathrm{~m}$, $\left.\mathrm{CH}_{2} \mathrm{CH}=\mathrm{CHCH}_{2}, 8 \mathrm{H}\right), 1.63\left(\mathrm{~m}, \mathrm{CH}_{2}, 4 \mathrm{H}\right), 1.1-1.4$ $\left(\mathrm{m}, \mathrm{CH}_{2}, 44 \mathrm{H}\right), 0.90\left(\mathrm{t}, J=6.8 \mathrm{~Hz}, \mathrm{CH}_{3}, 6 \mathrm{H}\right) ;{ }^{13} \mathrm{C}$ $\operatorname{NMR}\left(100 \mathrm{MHz}, \mathrm{CD}_{3} \mathrm{OD}\right) \delta 162.15(\mathrm{C}=\mathrm{O}), 132.88$ and $130.74(\mathrm{CH}=\mathrm{CHCH}=\mathrm{CH}), 130.06\left(\mathrm{CH}_{2} \mathrm{CH}=\mathrm{CHCH}_{2}\right)$, 40.78, 33.63, 33.07, 30.78, 30.47, 30.27, 28.87, 28.13, 27.51, and $23.74\left(\mathrm{CH}_{2}\right), 14.46\left(\mathrm{CH}_{3}\right)$; IR $(\mathrm{KBr}) 1592$ $\left(v_{\mathrm{C}=\mathrm{C}}\right), 1503\left(v_{\mathrm{C}=\mathrm{O}}\right) \mathrm{cm}^{-1}$.

10,12-Pentacosadiynylammonium (Z,Z)-muconate M-5. Colorless powder $\left(\mathrm{CH}_{3} \mathrm{OH}\right) ; \mathrm{mp} 114^{\circ} \mathrm{C}$ (decomp); ${ }^{1} \mathrm{HNMR}\left(400 \mathrm{MHz}, \mathrm{CD}_{3} \mathrm{OD}\right) \delta 7.41$ (m, $\left.\mathrm{C} \underline{H}=\mathrm{CHCO}_{2}, 2 \mathrm{H}\right), \quad 5.91 \quad\left(\mathrm{~m}, \quad \mathrm{CH}=\mathrm{C}_{\underline{H C O}}, 2 \mathrm{H}\right)$, $2.88\left(\mathrm{t}, J=7.6 \mathrm{~Hz}, \mathrm{NCH}_{2}, 4 \mathrm{H}\right), 2.24(\mathrm{t}, J=6.8 \mathrm{~Hz}$, $\left.\mathrm{CH}_{2} \mathrm{C} \equiv \mathrm{CCH}_{2}, 8 \mathrm{H}\right), \quad 1.64\left(\mathrm{~m}, \mathrm{CH}_{2}, 4 \mathrm{H}\right), 1.3-1.5$ $\left(\mathrm{m}, \mathrm{CH}_{2}, 64 \mathrm{H}\right), 0.90\left(\mathrm{t}, \quad J=6.8 \mathrm{~Hz}, \mathrm{CH}_{3}, 6 \mathrm{H}\right)$; ${ }^{13} \mathrm{C} N M R \quad\left(100 \mathrm{MHz}, \quad \mathrm{CD}_{3} \mathrm{OD}\right) \quad \delta \quad 162.32 \quad(\mathrm{C}=\mathrm{O})$, 133.20 and $130.51(\mathrm{CH}=\mathrm{CHCH}=\mathrm{CH}), 77.86$ and 66.38

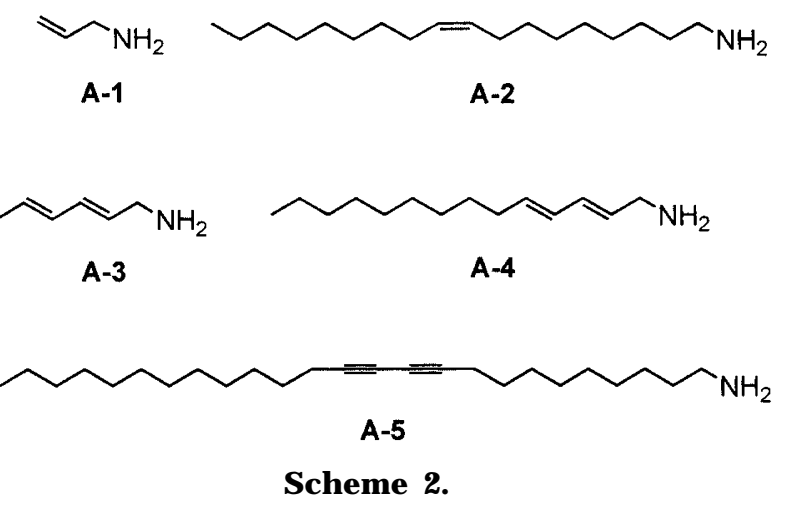

$(\mathrm{C} \equiv \mathrm{CC} \equiv \mathrm{C}), 40.89,33.11,30.70,30.62,30.49,30.36$, $30.16,30.06,29.85,29.52,29.03,27.48,23.76$, and $19.68\left(\mathrm{CH}_{2}\right), 14.46\left(\mathrm{CH}_{3}\right)$; IR $(\mathrm{KBr}) 1591\left(v_{\mathrm{C}=\mathrm{C}}\right), 1504$ $\left(v_{\mathrm{C}=\mathrm{O}}\right) \mathrm{cm}^{-1} ; \mathrm{UV}\left(\mathrm{CH}_{3} \mathrm{OH}\right) \lambda 258 \mathrm{~nm}(\varepsilon=16100)$.

\section{Synthesis of Unsaturated Amines}

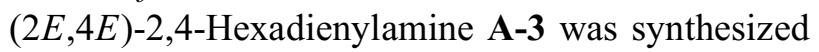
from sorbic acid according to the reactions in Scheme 3.

Sorbamide. Sorbic acid (4.0g) and thionyl chloride $(3 \mathrm{~mL})$ were refluxed for $1 \mathrm{~h}$. The obtained sorbic chloride was added dropwise to $28 \%$ aqueous ammonia $(20 \mathrm{~mL})$ with stirring below $0^{\circ} \mathrm{C}$. The reaction mixture was concentrated under reduced pressure, and the solid residue, a mixture of ammonium chloride and sorbamide, was washed with hot ethyl acetate $(100 \mathrm{~mL})$. When the ethyl acetate solution was collected and cooled to $-30^{\circ} \mathrm{C}$, the crystalline amide was obtained. Yield $1.81 \mathrm{~g}(46 \%)$. Colorless powder; mp $160-162{ }^{\circ} \mathrm{C} ;{ }^{1} \mathrm{HNMR}\left(400 \mathrm{MHz}, \mathrm{CDCl}_{3}\right)$ $\delta 7.52\left(\mathrm{~m}, \mathrm{CH}=\mathrm{CHCH}=\mathrm{CHCONH}_{2}, 1 \mathrm{H}\right), 6.67(\mathrm{~m}$, $\left.\mathrm{CH}_{3} \mathrm{C} \underline{\mathrm{H}}=\mathrm{C} \underline{\mathrm{HCH}}=\mathrm{CHCONH}_{2}, 2 \mathrm{H}\right), 6.36(\mathrm{~d}, J=15 \mathrm{~Hz}$, $\left.\mathrm{CH}=\mathrm{CHCH}=\mathrm{CHCONH}_{2}, 1 \mathrm{H}\right), 2.23\left(\mathrm{t}, J=5 \mathrm{~Hz}, \mathrm{CH}_{3}\right.$, $3 \mathrm{H})$.

$\boldsymbol{A}$-3. In a three-necked round-bottom flask equipped with a dropping funnel and a reflux condenser with a drying tube, sorbamide, $0.69 \mathrm{~g}$ in anhydrous ether $(10 \mathrm{~mL})$, was added dropwise under stirring over $1 \mathrm{~h}$ to the suspension of lithium aluminum hydride $(0.56 \mathrm{~g})$ in anhydrous ether $(10 \mathrm{~mL})$. The mixture was refluxed for $10 \mathrm{~h}$. Excess lithium aluminum hydride was carefully removed by after-treatment with water $(10 \mathrm{~mL})$ at $0^{\circ} \mathrm{C}$. The reaction mixture was filtered, and the solid was washed with anhydrous ether (several $100 \mathrm{~mL}$ portions). The ether solution was carefully concentrated at atmospheric pressure, because the product is also volatile. A-3 was obtained as a concentrated solution of diethyl ether, and the yield was determined by ${ }^{1}$ HNMR spectroscopy. Yield $0.137 \mathrm{~g}(25 \%)$. Colorless liquid: ${ }^{1} \mathrm{H}$ NMR $(400 \mathrm{MHz}$, $\left.\mathrm{CDCl}_{3}\right) \delta 6.07(\mathrm{~m}, \mathrm{CH}=\mathrm{C} \underline{\mathrm{HC}} \underline{\mathrm{H}}=\mathrm{CH}, 2 \mathrm{H}), 5.69(\mathrm{~m}$, $\left.\mathrm{CH}=\mathrm{CHCH}_{2} \mathrm{NH}_{2}, 1 \mathrm{H}\right), 5.42\left(\mathrm{~m}, \mathrm{CH}_{3} \mathrm{C} \underline{\mathrm{H}}=\mathrm{CH}, 1 \mathrm{H}\right)$, $3.31\left(\overline{\mathrm{m}}, \mathrm{CH}_{2}, 2 \mathrm{H}\right), 1.74\left(\mathrm{t}, J=6.8 \mathrm{~Hz}, \mathrm{CH}_{3}, 3 \mathrm{H}\right) ;{ }^{13} \mathrm{C}$ NMR $\left(100 \mathrm{MHz}, \mathrm{CDCl}_{3}\right) \delta 131.92,130.95,129.85$, and $128.43(\mathrm{CH}=\mathrm{CHCH}=\mathrm{CH}), 43.81\left(\mathrm{CH}_{2}\right), 17.89$ $\left(\mathrm{CH}_{3}\right)$.

(2E,4E)-2,4-Tetradecyldienylamine A-4 was synthesized according to the reactions in Scheme 4.

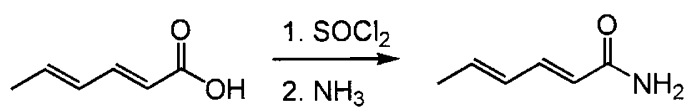

Scheme 3.

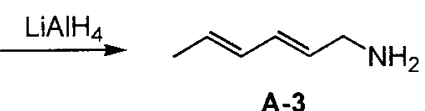

A-3 

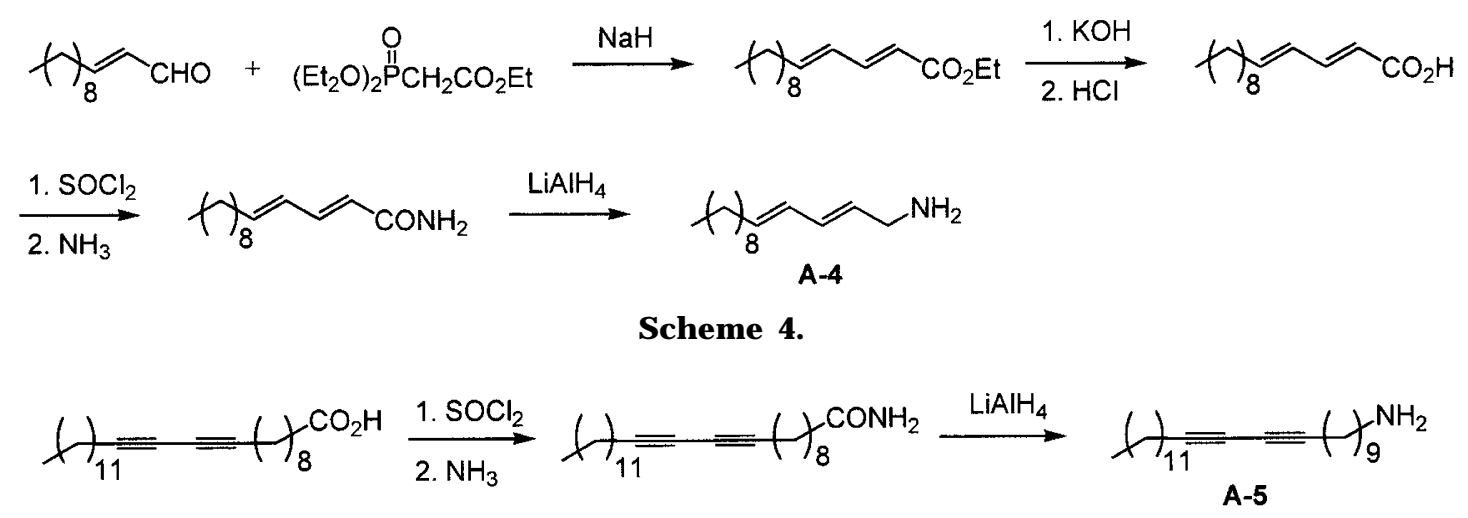

Scheme 5.

(2E,4E)-2,4-Tetradecadienoic Acid Ethyl Ester. To a three-necked flask equipped with a dropping funnel and a condenser, a $60 \%$ dispersion of sodium hydride in mineral oil $(0.802 \mathrm{~g})$ and dry tetrahydrofuran (THF) were charged in a dry nitrogen stream. To this suspension, triethyl phosphonoacetate (4.64 g) was added dropwise over $1 \mathrm{~h}$; the mixture was further stirred for $1 \mathrm{~h}$ at room temperature. The solution became clear. Then was added dropwise trans-2-dodecene-1al $(4.05 \mathrm{~g})$. The mixture was heated once at $60-65^{\circ} \mathrm{C}$, and then cooled to $15-20^{\circ} \mathrm{C}$. From a gummy precipitate, the product was extracted with a large amount of THF. The evaporation of the THF provided $(2 E, 4 E)-$ 2,4-tetradecadienoic acid ethyl ester as a yellow liquid. Yield $3.68 \mathrm{~g}(66 \%)$.

(2E,4E)-2,4-Tetradecadienoic Acid. A solution of (2E,4E)-2,4-tetradecadienoic acid ethyl ester (4.82 g) in methanol containing potassium hydroxide $(1.35 \mathrm{~g})$ and water (about $10 \mathrm{~mL}$ ) was heated under reflux for 1h. The cooled solution was diluted with water and acidified by addition of concentrated hydrochloric acid. The organic acid was extracted with ethyl acetate, and the extract was washed with a saturated sodium chloride solution. After the removal of the solvent, $(2 E, 4 E)$-2,4-tetradecadienoic acid was obtained. Yield $3.52 \mathrm{~g} \mathrm{(82 \% );} \mathrm{yellow} \mathrm{solid;}{ }^{1} \mathrm{H}$ NMR $\left(400 \mathrm{MHz}, \mathrm{CDCl}_{3}\right) \delta 7.35\left(\mathrm{~m}, \mathrm{CH}=\mathrm{CHCO}_{2} \mathrm{H}, 1 \mathrm{H}\right), 6.19$ $\left(\mathrm{m}, \mathrm{CH}=\mathrm{CHCH}=\mathrm{CHCO}_{2} \mathrm{H}, 2 \mathrm{H}\right), 5.78(\mathrm{~d}, J=15 \mathrm{~Hz}$, $\left.\mathrm{CH}=\mathrm{CHCO}_{2}, 1 \mathrm{H}\right), 2.17\left(\mathrm{~m}, \underline{\mathrm{CH}}_{2} \mathrm{CH}=\mathrm{CH}, 2 \mathrm{H}\right), 1.26-$ $1.34\left(\mathrm{~m}, \mathrm{CH}_{2}, 14 \mathrm{H}\right), 0.88\left(\mathrm{t}, J=6.9 \mathrm{~Hz}, \mathrm{CH}_{3}, 3 \mathrm{H}\right)$.

(2E,4E)-2,4-Tetradecadienamide.

$(2 E, 4 E)-2,4-$

Tetradecadienoic acid ( $3.52 \mathrm{~g})$ was reacted with thionyl chloride $(1.5 \mathrm{~mL})$, and then added dropwise to $28 \%$ aqueous ammonia $(20 \mathrm{~mL})$ below $0{ }^{\circ} \mathrm{C}$. $(2 E, 4 E)-2,4-$ Tetradecadienamide was extracted with chloroform, followed by recrystallization. Yield $2.85 \mathrm{~g}(89 \%)$. Light brown solid; ${ }^{1} \mathrm{HNMR}\left(400 \mathrm{MHz}, \mathrm{CDCl}_{3}\right) \delta 7.20$ $(\mathrm{m}, \mathrm{C} \underline{\mathrm{H}}=\mathrm{CHCO}, 1 \mathrm{H}), 6.13(\mathrm{~m}, \mathrm{C} \underline{\mathrm{H}}=\mathrm{C} \underline{\mathrm{HCH}}=\mathrm{CHCO}$, $2 \mathrm{H}), 5.79(\mathrm{~d}, J=15 \mathrm{~Hz}, \mathrm{CH}=\mathrm{CHCH}=\overline{\mathrm{C}} \mathrm{HCO}, 1 \mathrm{H})$, 5.33 (broad, $\left.\mathrm{NH}_{2}, 2 \mathrm{H}\right), 2.15\left(\mathrm{~m}, \mathrm{CH}_{2} \mathrm{CH}=\mathrm{CH}, 2 \mathrm{H}\right)$, $1.26-1.41\left(\mathrm{~m}, \mathrm{CH}_{2}, 14 \mathrm{H}\right), 0.87\left(\mathrm{t}, J=6.3 \mathrm{~Hz}, \mathrm{CH}_{3}\right.$, $3 \mathrm{H}) ;{ }^{13} \mathrm{C} \mathrm{NMR}\left(100 \mathrm{MHz}, \mathrm{CDCl}_{3}\right) \delta 168.32(\mathrm{C}=\mathrm{O})$, $144.33,142.89,128.00$, and $120.34(\mathrm{CH}=\mathrm{CHCH}=\mathrm{CH})$, $32.96,31.85,29.49,29.41,29.28,29.16,28.07$, and $22.65\left(\mathrm{CH}_{2}\right), 14.09\left(\mathrm{CH}_{3}\right)$.

$\boldsymbol{A - 4}$. To a suspension of lithium aluminum hydride $(0.43 \mathrm{~g})$ in anhydrous ether $(10 \mathrm{~mL}),(2 E, 4 E)$ 2,4-tetradecadienamide $(0.87 \mathrm{~g})$ in anhydrous ether $(10 \mathrm{~mL})$ was added dropwise under stirring over $1 \mathrm{~h}$. The mixture was refluxed for $10 \mathrm{~h}$. After treatment similar to the synthesis of A-3, the reaction mixture was filtered, and a solid was washed with anhydrous ether (several $100 \mathrm{~mL}$ portions). The ether was evaporated under reduced pressure. Yield $0.39 \mathrm{~g}$ (49\%). Light yellow liquid; ${ }^{1} \mathrm{HNMR}$ $\left(400 \mathrm{MHz}, \mathrm{CDCl}_{3}\right) \delta 6.07(\mathrm{~m}, \quad \mathrm{CH}=\mathrm{C} \underline{\mathrm{HC}} \underline{\mathrm{H}}=\mathrm{CH}$, $2 \mathrm{H}), 5.66\left(\mathrm{~m}, \quad \mathrm{CH}=\mathrm{CHCH}_{2} \mathrm{NH}_{2}, 1 \mathrm{H}\right), \overline{5} . \overline{46} \quad(\mathrm{~m}$, $\left.\mathrm{CH}=\mathrm{CHCH}=\mathrm{CHCH}_{2} \mathrm{NH}_{2}, 1 \mathrm{H}\right), 3.32\left(\mathrm{~m}, \mathrm{CH}_{2} \mathrm{NH}_{2}\right.$, $2 \mathrm{H}), 1.98\left(\mathrm{~m}, \quad \underline{\mathrm{CH}}_{2} \mathrm{CH}=\mathrm{CHCH}=\mathrm{CHCH}_{2} \mathrm{NH}_{2}, 2 \mathrm{H}\right)$, $1.21-1.48\left(\mathrm{~m}, \mathrm{CH}_{2}, 14 \mathrm{H}\right), 0.88\left(\mathrm{t}, J=6.8 \mathrm{~Hz}, \mathrm{CH}_{3}\right.$, $3 \mathrm{H}) ;{ }^{13} \mathrm{C} \mathrm{NMR}\left(100 \mathrm{MHz}, \mathrm{CDCl}_{3}\right) \delta 134.42,132.07$, 130.14, and $129.55(\mathrm{CH}=\mathrm{CHCH}=\mathrm{CH}), 43.87,32.57$, 31.86, 29.53, 29.28, 25.28, and $22.63\left(\mathrm{CH}_{2}\right), 14.07$ $\left(\mathrm{CH}_{3}\right)$.

10,12-Pentacosadiynylamine A-5 was synthesized according to the reactions in Scheme 5.

10,12-Pentacosadiynamide. Commercially available 10,12-pentacosadiynoic acid (4.0 g) was reacted with thionyl chloride $(1 \mathrm{~mL})$, and the obtained acid chloride was added dropwise to $28 \%$ aqueous ammonia $(20 \mathrm{~mL}) .10,12-$ Pentacosadiynamide was extracted and recrystallized with chloroform. Yield $3.04 \mathrm{~g}(76 \%)$. Colorless powder; mp $99-102{ }^{\circ} \mathrm{C}\left(\mathrm{CHCl}_{3}\right)$; ${ }^{1} \mathrm{HNMR}$ $\left(400 \mathrm{MHz}, \mathrm{CDCl}_{3}\right) \delta 5.37$ (broad, $\left.\mathrm{NH}_{2}, 2 \mathrm{H}\right), 2.20-$ $2.26\left(\mathrm{~m}, \mathrm{CH}_{2} \mathrm{CONH}_{2}, \mathrm{CH}_{2} \mathrm{C} \equiv \mathrm{C}, 6 \mathrm{H}\right), 1.48\left(\mathrm{~m}, \mathrm{CH}_{2}\right.$, $4 \mathrm{H}), 1.25-1.37\left(\mathrm{~m}, \mathrm{CH}_{2}, 28 \mathrm{H}\right), 0.88(\mathrm{t}, J=7.3 \mathrm{~Hz}$, $\left.\mathrm{CH}_{3}, 3 \mathrm{H}\right)$.

A-5 was synthesized by the reduction of the amide according to a procedure similar to that for $\mathbf{A - 3}$ or $\mathbf{A - 4}$, followed by recrystallization from methanol. 
Yield $0.42 \mathrm{~g} \mathrm{(77 \% ).} \mathrm{Colorless} \mathrm{powder;} \mathrm{mp} \mathrm{71-}$ $73{ }^{\circ} \mathrm{C}\left(\mathrm{CH}_{3} \mathrm{OH}\right) ;{ }^{1} \mathrm{HNMR}\left(400 \mathrm{MHz}, \mathrm{CDCl}_{3}\right) \delta 2.67$ (t, $\left.J=7 \mathrm{~Hz}, \underline{\mathrm{C}}_{2} \mathrm{NH}_{2}, 2 \mathrm{H}\right), 2.24$ (t, $J=7 \mathrm{~Hz}$, $\left.\mathrm{CH}_{2} \mathrm{C} \equiv \mathrm{CC} \equiv \mathrm{CCH}_{2}, 4 \mathrm{H}\right), 1.51\left(\mathrm{~m}, \mathrm{CH}_{2}, 4 \mathrm{H}\right), 1.25-$ $1.36\left(\mathrm{~m}, \mathrm{CH}_{2}, 30 \mathrm{H}\right), 0.88\left(\mathrm{t}, J=7.3 \mathrm{~Hz}, \mathrm{CH}_{3}\right.$, $3 \mathrm{H}) ;{ }^{13} \mathrm{C}$ NMR $\left(100 \mathrm{MHz}, \mathrm{CDCl}_{3}\right) \delta 77.51$ and 65.18 $(\mathrm{C} \equiv \mathrm{CC} \equiv \mathrm{C}), 41.95,33.31,31.88,29.59,29.39,29.06$, 28.80, 28.31, 26.81, 22.65, and $19.16\left(\mathrm{CH}_{2}\right), 14.09$ $\left(\mathrm{CH}_{3}\right)$.

\section{Synthesis of PMA}

The photopolymerization of dodecylammonium $(Z, Z)$-muconate was carried out in the crystalline state under UV irradiation with a high-pressure mercury lamp (Toshiba SHL-100-2, 100 W) at a distance of $10 \mathrm{~cm}$ through a Pyrex filter. ${ }^{21}$ The resulting polymer was isolated by removing the unreacted monomer with methanol. The hydrolysis of poly(dodecylammonium muconate) was carried out in $\mathrm{HCl}$ methanol solution $\left(1 \mathrm{~mol} \mathrm{~L}^{-1}\right)$ with stirring at room temperature for $1 \mathrm{~h}$. IR spectroscopy confirmed the quantitative transformation. PMA: IR (KBr) $1712\left(v_{\mathrm{C}=\mathrm{O}}\right) \mathrm{cm}^{-1}$.

\section{Intercalation}

A typical procedure for the intercalation is as follows. ${ }^{23}$ The PMA crystals, $50 \mathrm{mg}$, were dispersed in methanol solution $(20 \mathrm{~mL})$ of a desired amount of amine and stirred at room temperature for $1 \mathrm{~h}$. The polymer crystals were isolated with a glass filter, washed with a small amount of fresh methanol ( $c a$. $10 \mathrm{~mL}$ ), and dried in vacuo. The conversion was gravimetrically determined. The fraction of the ammonium carboxylate in the polymer crystals was also confirmed by IR spectroscopy.

Polymer prepared by intercalation of A-1 into PMA: IR $(\mathrm{KBr}) 1567\left(v_{\mathrm{C}=\mathrm{O}}\right), 995\left(\delta_{\text {trans }-\mathrm{CH}=\mathrm{CH}}\right) \mathrm{cm}^{-1}$.

Polymer prepared by intercalation of A-2 into PMA: IR (KBr) $1567\left(v_{\mathrm{C}=\mathrm{O}}\right), 994\left(\delta_{\text {trans }-\mathrm{CH}=\mathrm{CH}}\right) \mathrm{cm}^{-1}$.

Polymer prepared by intercalation of A-5 into PMA: IR $(\mathrm{KBr}) 1566\left(v_{\mathrm{C}=\mathrm{O}}\right), 998\left(\delta_{\text {trans }-\mathrm{CH}=\mathrm{CH}}\right) \mathrm{cm}^{-1}$.

\section{Photoreactions of $\mathbf{M - 1}, \mathbf{M}-\mathbf{2}$, and $\mathbf{M}-5$}

The monomers were photoirradiated with a UV lamp in the crystalline state. The isomerization of M-1 was examined by ${ }^{1} \mathrm{H}$ NMR spectroscopy. The polymers from M-2 and M-5 were isolated by removing the unreacted monomers with chloroform.

Polymer prepared by the topochemical polymerization of M-2: IR ( $\mathrm{KBr}) 1569\left(v_{\mathrm{C}=\mathrm{O}}\right), 996\left(\delta_{\text {trans }-\mathrm{CH}=\mathrm{CH}}\right)$ $\mathrm{cm}^{-1}$.

Polymer prepared by the topochemical polymerization of M-5: IR (KBr) $1566 \quad\left(v_{\mathrm{C}=\mathrm{O}}\right), 1001$ $\left(\delta_{\text {trans }-\mathrm{CH}=\mathrm{CH}}\right) \mathrm{cm}^{-1}$.

\section{Isolation of Photoproducts from Polymer Side Chains}

Polymer was prepared by the intercalation of A2 into PMA or by the polymerization of M-2. The polymer was photoirradiated in the crystalline state for $100 \mathrm{~h}$ at room temperature. After the irradiation, the polymer was immersed into a methanol solution of $\mathrm{HCl}$ $\left(1 \mathrm{~mol} \mathrm{~L}^{-1}\right)$. The insoluble PMA was recovered, and the filtrate was extracted with diethyl ether under the condition of $\mathrm{pH}>12$. The photoproduct isolated as an oily compound was reacted with acetyl chloride to give the corresponding acetamide derivative. The products were precipitated with a large amount of diethyl ether and isolated as a powdery compound, and then provided for gel permeation chromatography (GPC) measurement. The number-average molecular weights $\left(M_{\mathrm{n}}\right)$ were 963 and 626 for the photoproducts isolated from the polymers obtained by the topochemical polymerization of M-2 and by the intercalation of A-2, respectively.

\section{Measurements}

NMR spectra were recorded on a JOEL JMN A400 spectrometer in $\mathrm{CDCl}_{3}$ or $\mathrm{CD}_{3} \mathrm{OD}$ at an ambient temperature. IR spectra were taken with a JASCO FT/IR 430 spectrometer. Wide-angle X-ray diffraction profile was measured on a RIGAKU X-ray diffractometer RINT-Ultima 2100 with $\mathrm{Cu}-\mathrm{K} \alpha$ radiation. $\gamma$-Ray irradiation was carried out with ${ }^{60} \mathrm{Co}$ at the Research Institute for Advanced Science and Technology, Osaka Prefecture University. GPC was performed with a Tosoh GPC- 8000 series system at $38^{\circ} \mathrm{C}$ in THF as an eluent and calibrated with standard polystyrenes. UVvis spectroscopy was taken with a JASCO V-550 spectrophotometer.

\section{RESULTS AND DISCUSSION}

The intercalation of several unsaturated amines A-1 to A-5 (Scheme 2) was carried out with PMA as the host polymer crystals. The corresponding saturated $n$ alkylamines possessing an identical number of carbons in the alkyl chain were also used as the guest amines for comparison. ${ }^{23}$ The results are summarized in Table I.

Figure 1 shows the effects of the molar ratio of the used amine against the carboxylic acid $\left(\left[-\mathrm{NH}_{2}\right] /\right.$ $\left.\left[-\mathrm{CO}_{2} \mathrm{H}\right]\right)$ in the host polymer on the conversion from the acid to the ammonium form during the intercalation of the saturated and unsaturated amines. When longchain amines were reacted, both of the saturated and unsaturated amines showed a similar reaction behavior. For example, the intercalation of A-2 and A-9 as the long-chain guest molecules $(m=18)$ easily provided the ammonium polymer crystals in a high conversion 
Table I. Intercalation of unsaturated and saturated amines using poly(muconic acid) crystals as the host

\begin{tabular}{|c|c|c|c|c|}
\hline $\mathrm{RNH}_{2}$ & $\begin{array}{c}{\left[-\mathrm{NH}_{2}\right] /\left[-\mathrm{CO}_{2} \mathrm{H}\right]} \\
(\mathrm{mol} / \mathrm{mol})\end{array}$ & $\begin{array}{l}\text { Time } \\
\text { (h) }\end{array}$ & $\begin{array}{l}\text { Conv. } \\
(\%)\end{array}$ & $\begin{array}{c}d \text {-value } \\
(\AA)\end{array}$ \\
\hline \multirow[t]{2}{*}{$\mathrm{CH}_{2}=\mathrm{CHCH}_{2} \mathrm{NH}_{2}(\mathbf{A - 1})$} & 1 & 1 & 20.2 & 7.0 \\
\hline & 10 & 1 & 83.5 & 8.4 \\
\hline \multirow[t]{2}{*}{$(9 \mathrm{Z})-\mathrm{CH}_{3}\left(\mathrm{CH}_{2}\right)_{7} \mathrm{CH}=\mathrm{CH}\left(\mathrm{CH}_{2}\right)_{8} \mathrm{NH}_{2}(\mathbf{A}-2)$} & 1 & 1 & 93.7 & 42.4 \\
\hline & 10 & 1 & 93.1 & 42.4 \\
\hline$(2 E, 4 E)-\mathrm{CH}_{3} \mathrm{CH}=\mathrm{CHCH}=\mathrm{CHCH}_{2} \mathrm{NH}_{2}(\mathbf{A}-\mathbf{3})$ & 5 & 8 & 85.9 & 12.5 \\
\hline$(2 E, 4 E)-\mathrm{CH}_{3}\left(\mathrm{CH}_{2}\right)_{8} \mathrm{CH}=\mathrm{CHCH}=\mathrm{CHCH}_{2} \mathrm{NH}_{2}(\mathbf{A}-4)$ & 1 & 8 & 86.9 & 23.4 \\
\hline $\mathrm{CH}_{3}\left(\mathrm{CH}_{2}\right)_{11} \mathrm{C} \equiv \mathrm{CC} \equiv \mathrm{C}\left(\mathrm{CH}_{2}\right)_{9} \mathrm{NH}_{2}(\mathbf{A}-\mathbf{5})$ & 1 & 2 & 76.8 & 56.5 \\
\hline \multirow[t]{2}{*}{$\mathrm{CH}_{3}\left(\mathrm{CH}_{2}\right)_{2} \mathrm{NH}_{2}(\mathbf{A}-\mathbf{6})^{\mathrm{b}}$} & 1 & 1 & 49.6 & - \\
\hline & 10 & 1 & 92.2 & 9.5 \\
\hline \multirow[t]{2}{*}{$\mathrm{CH}_{3}\left(\mathrm{CH}_{2}\right)_{5} \mathrm{NH}_{2}(\mathbf{A}-7)^{\mathrm{b}}$} & 1 & 1 & 71.4 & 20.5 \\
\hline & 10 & 1 & 89.3 & 20.5 \\
\hline \multirow[t]{2}{*}{$\mathrm{CH}_{3}\left(\mathrm{CH}_{2}\right)_{13} \mathrm{NH}_{2}(\mathbf{A}-\mathbf{8})^{\mathrm{b}}$} & 1 & 1 & 79.6 & 36.1 \\
\hline & 10 & 1 & 95.1 & 36.1 \\
\hline \multirow{2}{*}{$\mathrm{CH}_{3}\left(\mathrm{CH}_{2}\right)_{17} \mathrm{NH}_{2}(\mathbf{A}-\mathbf{9})^{\mathrm{b}}$} & 1 & 1 & 91.6 & 45.0 \\
\hline & 10 & 1 & 96.4 & 45.0 \\
\hline
\end{tabular}

${ }^{\mathrm{a}}$ Interlayer spacing value of the obtained ammonium polymer crystals. ${ }^{\mathrm{b}}$ From ref 23.

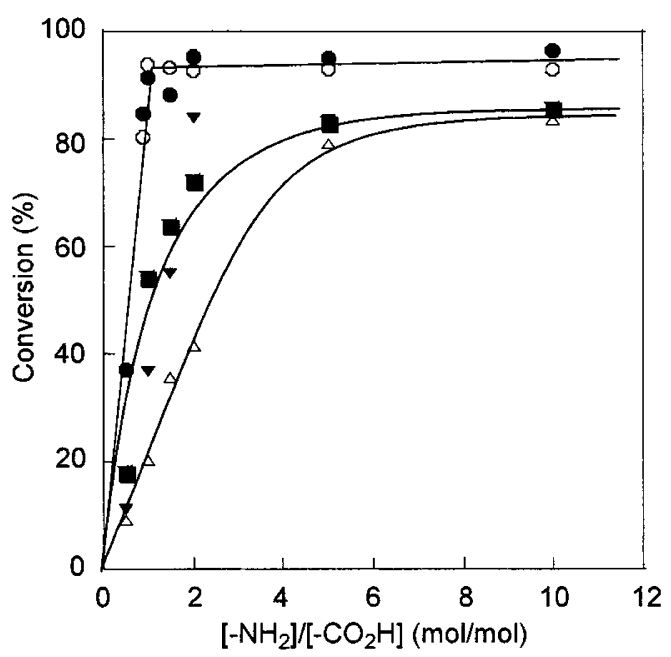

Figure 1. Effect of the amount of the used amines on the conversion during the intercalation. $(\Delta) \mathbf{A}-\mathbf{- 1},(\bigcirc) \mathbf{A}-\mathbf{2},(\mathbf{O}) \mathbf{A}-\mathbf{9},(\mathbf{0})$ $n$-butylamine, and $(\mathbf{\nabla})$ ethylamine. Reaction time, $1 \mathrm{~h}$; stirred in methanol dispersion at room temperature.

over $90 \%$, irrespective of the amount of the used amine. Here, $m$ is the carbon number of the used amines. The reaction proceeded within a short time independent of the presence or absence of the unsaturated group in the amine, as shown in a time-conversion relationship (Figure 2). This result indicates that the existence of a cisdouble bond gives no effect on the intercalation reactivity due to the high reactivity of the long-chain guest molecules. In contrast to the facile intercalation of the long-chain saturated and unsaturated amines, the conversion of A-1 to the ammonium polymer was dependent on the amount of the used amine. The intercalation ability of A-1 was lower than those of the saturated amines with a similar short carbon chain $(m=2-4)$, as shown in the results in Figure 1 and Table I. It is possibly due to a difference in molecular packing in the

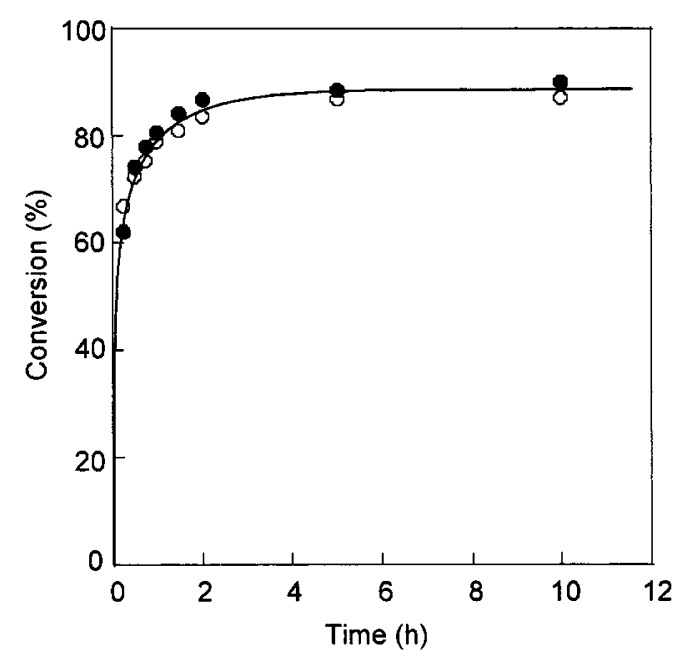

Figure 2. Effect of the reaction time on the conversion during the intercalation of $(\bigcirc) \mathbf{A - 2}$ and $(\bullet)$ A-9. $\left[-\mathrm{NH}_{2}\right] /\left[-\mathrm{CO}_{2} \mathrm{H}\right]=1$; stirred in methanol dispersion at room temperature.

interlayer space; a decrease in the flexibility of the unsaturated amine molecule due to the presence of a rigid double bond.

During the intercalation of A-3, A-4, and A-5 as the diene and diyne compounds as the guests, all the amines were incorporated into PMA in a high conversion $(77-87 \%)$ under appropriate conditions, namely, the amount of the amine and the reaction time. The intercalation yield increased according to the chain length of the amine; that is, the reactivity was in the order of A-3 $<\mathbf{A - 4}<\mathbf{A}-5$. As a result of it, A-5 was readily intercalated with a smaller amount of the used amine within a shorter reaction time (Table I).

The interlayer spacing values ( $d$-values) were determined by the powder X-ray diffraction measurement of the intercalated polymer crystals. The $d$-values are shown in Table I. As previously reported, ${ }^{23}$ the $d$-value 


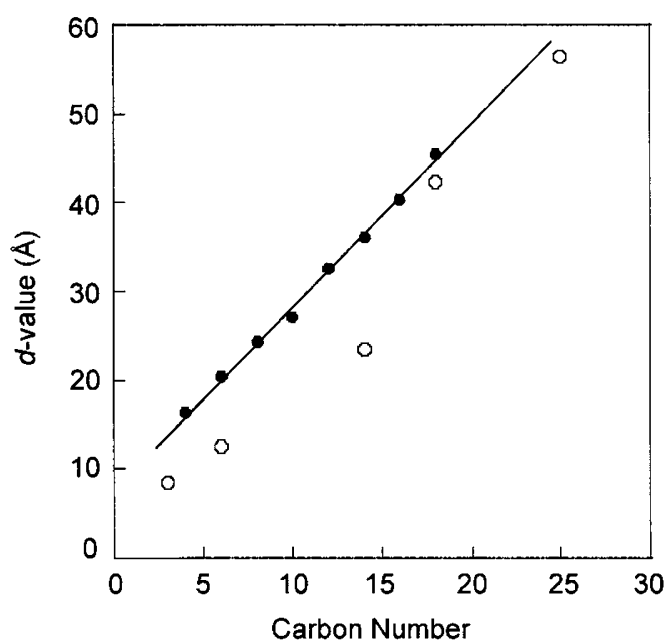

Figure 3. Interlayer spacing $(d)$ values for the polymer crystals intercalated with various amines. $(\bigcirc)$ Unsaturated amines in this work, (๑) n-alkylamines including A-6 to A-9 (ref 23).

is dependent on the size of the intercalated amines for a series of $n$-alkylamines. The $d$-value increased linearly with the carbon number of the amine and the thickness of the ammonium layer increases by $1.0 \AA$ for each carbon in the $\mathrm{N}$-alkyl substituent. Furthermore, we concluded that the alkyl chains of the amines are stacked in the layer with a similar tilt structure. In this work, a smaller $d$-value was always observed for the unsaturated ammonium polymer crystals than that for the corresponding saturated one, as shown in Figure 3. This is interpreted by the different structure of the carbon chains of the saturated and unsaturated amines. Namely, the unsaturated amines favor a stacking structure with a greater tilt angle, compared with that of the saturated amines.

The photoreaction of the polymer crystals intercalated with A-2 as the unsaturated amine was carried out under UV irradiation with a high-pressure mercury lamp at room temperature. A change in the IR spectrum was observed during UV irradiation, indicating the process of the reaction of an oleyl group in the side chain. On the other hand, the polymer crystals intercalated with A-1 was inert under similar photoirradiation conditions, although a terminal $\mathrm{C}=\mathrm{C}$ bond was expected to be more reactive than the internal olefin bond of A-2. The $\gamma$-ray radiation of the polymer crystals intercalated with A-1 was also carried out, but the allyl group again had no reaction.

To further investigate a difference in the photoreactivity of the polymer crystals intercalated with A-1 and A-2, we tried to prepare similar ammonium polymer crystals through the topochemical polymerization of the corresponding ammonium monomer crystals. The ammonium monomers M-1 and M-2 (Scheme 6) were readily prepared by mixing the muconic acid and A-1
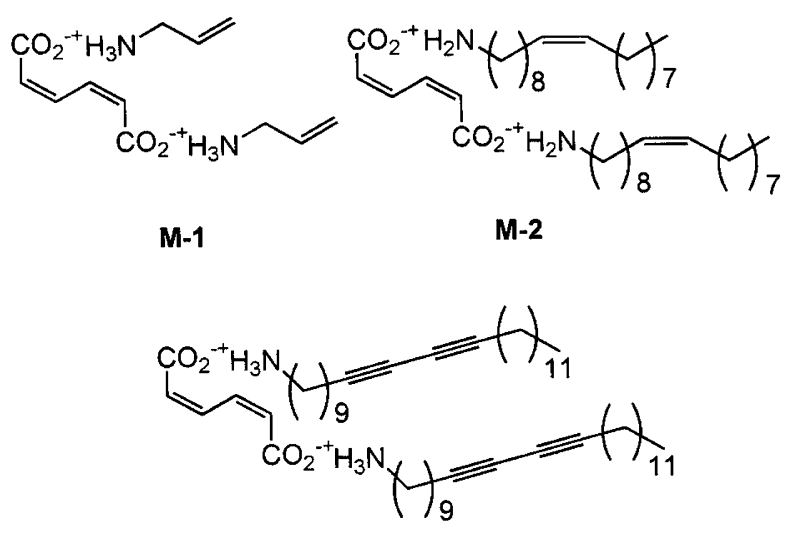

M-5

\section{Scheme 6.}

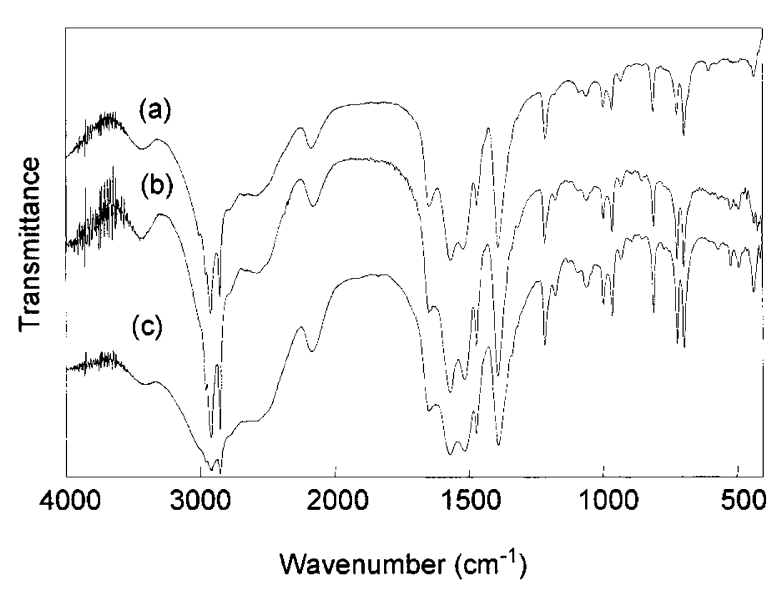

Figure 4. IR spectra of poly(oleylammonium muconate) obtained by (a) intercalation of A-2 with PMA crystals, (b) topochemical polymerization of M-2 under UV-irradiation without a Pyrex filter $(\lambda<280 \mathrm{~nm})$, and (c) topochemical polymerization of $\mathbf{M - 2}$ under UV-irradiation with a Pyrex filter $(\lambda>280 \mathrm{~nm})$.

or A-2. Recrystallization from methanol provided powdery and needle crystals for M-1 and M-2, respectively.

A change in the IR spectrum of M-1 was observed during the photoirradiation, but the spectrum of the photoproduct was different from that of the intercalated polymers. ${ }^{1}$ H NMR spectrosopy confirmed the isomerization of M-1, but not polymerization. This is in good agreement with the fact that short-chain alkylammonium $(Z, Z)$-muconates $(m<9)$ isomerize to the corresponding isomers under photoirradiation in the crystalline state, while long-chain alkylammonium $(Z, Z)$ muconates $(10>m)$ polymerize topochemically under similar conditions in our previous results. ${ }^{21,28}$ Differing from the isomerization of $\mathbf{M}-\mathbf{1}$, the oleylammonium monomer M-2 topochemically polymerized to give an insoluble product under UV-irradiation in the crystalline state as expected. Figure 4 shows the IR spectra of the poly(oleylammonium muconate)s obtained by the intercalation and the polymerization. After the photoirradiation of M-2, the peak based on stretching of the 


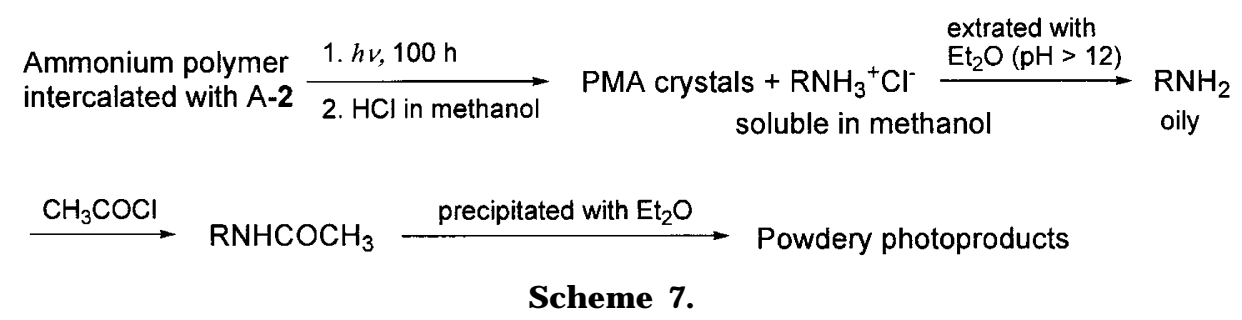

conjugated double bond of the monomer at $1592 \mathrm{~cm}^{-1}$ disappeared, and a new peak due to the out-of-plain deformation vibration of a trans double bond was observed at $996 \mathrm{~cm}^{-1}$. The shift of the peak of the carbonyl stretching was observed from $1503 \mathrm{~cm}^{-1}$ of the monomer to $1569 \mathrm{~cm}^{-1}$ of the polymer. In order to prevent the simultaneous reaction of the inner double bond in the side chain during photoirradiation, photoirradiation was carried out by an incident light with a limited wavelength $(\lambda>280 \mathrm{~nm})$ using a Pyrex filter. The limited irradiation $(\lambda>280 \mathrm{~nm})$ was expected to give a polymer with a structure similar to the polymer intercalated with A-2 into the PMA crystals. The photoirradiation at a higher wavelength cannot induce the polymerization of an oleyl group, which is a non-conjugated olefin. ${ }^{29}$ Contrary to expectation, however, the spectra shown in Figures $4 b$ and $4 c$ are similar to each other. The spectra of the polymers obtained by photopolymerization are also similar to that of the polymer obtained by the intercalation (Figure 4a). We have consequently concluded that the polymer crystals having unsaturated groups in the countercation are produced by not only the intercalation of A-2 into PMA but also the topochemical polymerization of M-2 irrespective of the photoirradiation conditions. When $\gamma$-rays were irradiated the crystals of $\mathbf{M - 2}$, the polymerization proceeded and gave a polymer in $86 \%$ yield, similar to the photoreaction. We expected that $\gamma$-ray radiation induced the polymerizations of the muconate groups to make the muconate polymer chain and also of the oleyl groups in the side chain, due to the high potential energy of the $\gamma$-radiation for the chemical reactions, but with low selectivity. Nevertheless, it has been revealed that a large amount of unreacted oleyl groups still remained in the side chain of the isolated polymer after the radiation. This result indicates that the considerably low reactivity of the oleyl group in the constrained interlayer space even under $\gamma$-ray irradiation with high energy.

To quantitatively evaluate the reactivity of the oleyl moiety incorporated between the polymer sheets in the PMA crystals, the photoproduct was isolated from the host polymers after photoirradiation. The ${ }^{1} \mathrm{H} N \mathrm{NR}$ and IR spectra of the isolated reaction products suggested the reaction of the inner double bond in the side chain of the polymer crystals during the UV irradiation, judging from a change in the peak intensity of the unsaturated group. The molecular weight of the isolated products was determined by GPC after they were reacted with acetyl chloride to avoid the absorption of the amine to gels in a GPC column, according to the procedures as shown in Scheme 7 (See also experimental). The elution curves consisted of peaks due to $N$-oleylacetamide and its oligomers, indicating that the countercation was partly oligomerized during the UV irradiation. The $M_{\mathrm{n}}$ value of the oligomeric photoproduct $\left(M_{\mathrm{n}}=963\right) \mathrm{ob}-$ tained by the topochemical polymerization was higher than that obtained via the intercalation process $\left(M_{\mathrm{n}}=\right.$ 626). It suggests that the oleyl groups are more regularly arranged in the polymer crystals obtained by the direct polymerization of M-2. Thus, the oleyl moiety of the guest amine provided oligomers but not a high molecular weight polymer, indicating that an inner double bond in the side chain slowly reacts in the interlayer constrained reaction locus. The less reactivity is considered to be because the stacking distance of the amines along the muconate polymer chains is greater than the ideal one for the reaction between the olefin compounds. Figure 5 shows the summary of the reaction pathways of the ammonium crystals using unsaturated amines as the countercations. The allyl groups introduced in the polymer are irregularly packed in the interlayer space, resulting in no reaction during the later photoirradiation. The oleyl groups as the long-chain substituent are regularly stacked in a style similar to a bimolecular membrane structure, but the repeating distance is too long to produce a high molecular weight polymer.

Next, the photoreaction of the polymer crystal intercalated with A-3 as the diene-containing amine was carried out. In the IR spectrum, the peak based on stretching of the conjugated double bond at 1610 and $1649 \mathrm{~cm}^{-1}$ disappeared and a new peak of the outof-plain deformation vibration based on a trans double bond was observed at $972 \mathrm{~cm}^{-1}$ after the irradiation. Similar photoreaction behavior was also observed for the polymer crystal intercalated with A-4. These changes in the IR spectra suggest the polymerization of the unsaturated functional groups in the side chain of the polymer crystals. The diene moieties are probably 


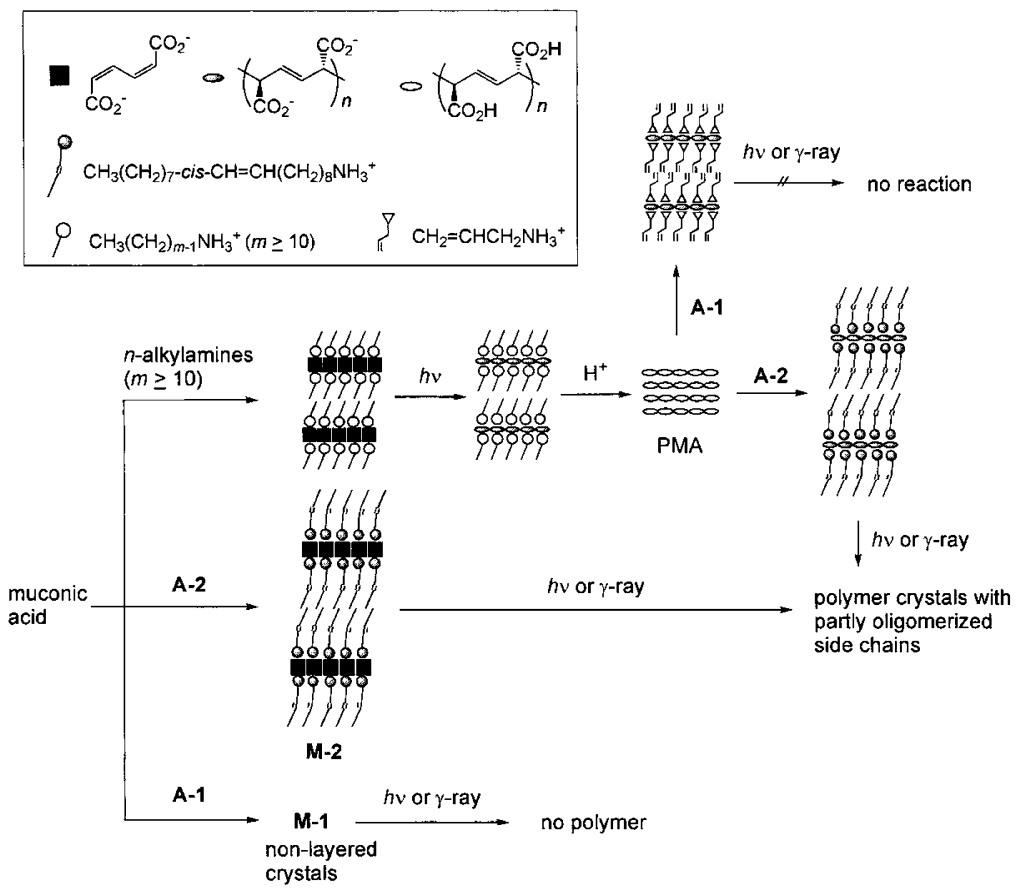

Figure 5. Schematic reaction pathways for the photoreactions of the ammonium crystals with an unsaturated moiety in the side chain as the ammonium cations.

stacked in the layers along with the polymer chains with a stacking distance of $4.9 \AA$ appropriate for the polymerization of diene monomers. ${ }^{25,26}$ We tried to evaluate the conversion and the molecular weight of the polymers produced from the reaction of countercation parts in the side chain, but the isolation of the side-chain photoproducts failed. The produced polymers may be of high molecular weight and include strong polymerpolymer interactions, which show high resistance to hydrolysis. Judging from the change in the IR spectrum, the side-chain diene groups are converted into the polymer in a high yield.

It is well known that a diacetylene polymerizes in the solid state under irradiation by $\gamma$-rays or upon heating when monomer molecules stack with a distance of $5 \AA$, similar to the diene polymerizations. ${ }^{30,31}$ The reaction of the diacetylene-containing polymer crystals, obtained by intercalation with A-5, was carried out under UV, $\gamma$-, and X-ray irradiation, or upon heating. The color of the polymer crystals changed from colorless to blue or red after irradiation or heating. This color change is one piece of evidence for topochemical polymerization of diyne compounds, as has been reported in literature. ${ }^{32-35}$ In addition to coloring, a small change in the X-ray powder diffraction profile was also observed; the $d$-value changed from $56.5 \AA$ before $\gamma$-radiation to $55.8 \AA$ after the reaction. A similar but slightly smaller $d$-value of the polymer crystal after $\gamma$-ray irradiation supports the topochemical polymerization, being the same as the behavior of other diene and diyne polymerizations. To confirm the re-

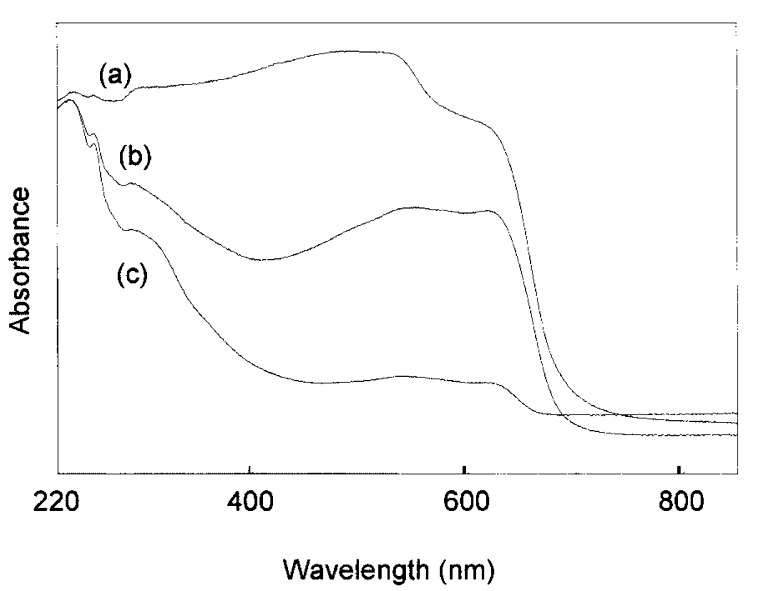

Figure 6. UV-vis diffusion reflectance spectra of the polymer crystals intercalated with A-5 into PMA crystals. (a) After $\gamma$ radiation $(200 \mathrm{kGy}),(\mathrm{b})$ after UV-irradiation $(8 \mathrm{~h})$, and (c) before irradiation.

action, UV-vis diffusion reflectance measurement was carried out. The absorption spectra are shown in Figure 6. To compare the spectra of the polymer before and after the UV and $\gamma$-ray irradiations, the intensity of the absorption at 550 and $620 \mathrm{~nm}$ increased due to the formation of a conjugated chain structure. Moreover, the thermochromism of polydiynes was observed during the polymerization; the absorption band shifted to a shorter wavelength region during the process of the $\gamma$ - and UV-polymerization. A color also changed from blue to red when the isolated polymer at a low conversion was heated at $150^{\circ} \mathrm{C}$. We conclude that the thermochromic transition is associated with a conformational change of the polydiyne backbone from planar 


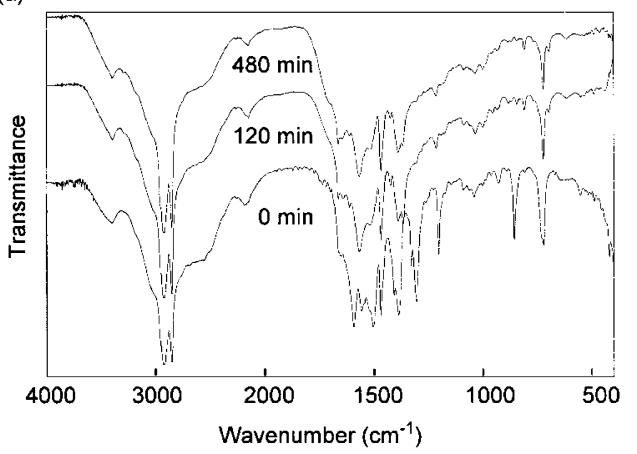

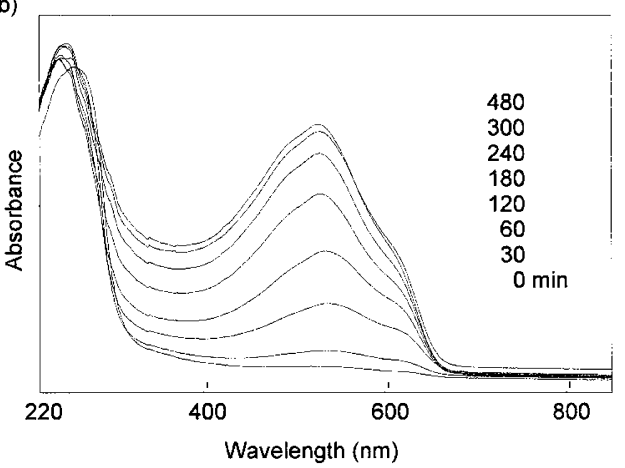

Figure 7. Change in (a) IR spectrum and (b) UV-vis diffusion reflectance spectrum during the polymerization of M-5 in the crystalline state. Photoirradiation time, $0-480 \mathrm{~min}$.

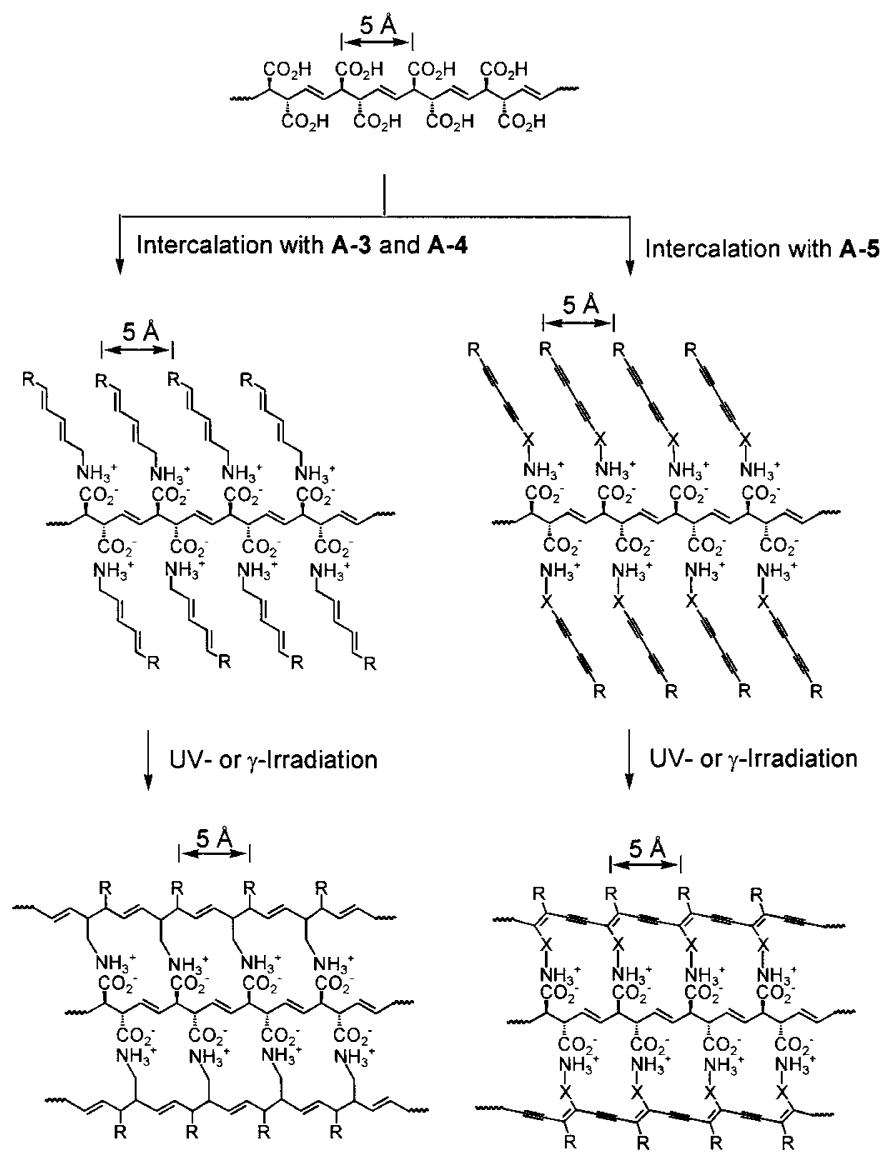

Figure 8. Reaction profiles for the UV and $\gamma$-irradiation of the dienyl and diynyl amines (A-3 $\sim \mathbf{A}-\mathbf{5})$ introduced into PMA crystals as the countercations. The arrangement of the counter ammonium including diene and diyne moieties at a stacking distance of $5 \AA$ results in the interlayer polymerization between the polymuconate layers in the crystals.

to non-planar, induced by the change in the alkyl chain conformation.

We also examined the UV-polymerization of the monomer M-5 (Scheme 6). IR and UV-vis spectra (Figure 7) have evidenced that the polymerization of M-5 proceeds to give the polymer consisting of polymuconate and polydiacetylene sheets which are alternatingly stacked in the crystals during the irradiation. Namely, in the IR spectrum of $\mathbf{M - 5}$, a peak due to conjugating $\mathrm{C}=\mathrm{C}$ bond at $1591 \mathrm{~cm}^{-1}$ disappeared and a peak due to the carbonyl stretching shifted from 1504 to $1561 \mathrm{~cm}^{-1}$ during the UV irradiation. The diene moieties completely polymerized during the 2 -h irradiation. Any change in the diyne moiety cannot be monitored during the polymerization by the IR spectroscopy, due to the symmetric structure of the diyne and resulting polydiyne groups. From the change in the UV-vis absorption spectrum during photoirradiation, it was revealed that the polymerization of the diyne groups proceeded slowly compared to the polymerization of diene groups. On the other hand, the $\gamma$-radiation resulted in the alternatingly stacked polymer crystals in a quan- 
titative yield. We are further investigating the polymerization kinetics of ammonium derivatives including diyne and diene moieties and the crystal structure and some properties characterization of the resulting layered polymer crystals with an alternatingly stacked polymer sheet structure. More detailed results of alternatingly stacked polymer crystals will be separately reported in future.

In conclusion, we have demonstrated that 1,3-dienyland 1,3-diynylamines are intercalated into the interlayers of the host polymers, and that the guest molecules are stacked to make a columnar structure in a stacking distance of $5 \AA$ in the interlayer constrained space. The stacking distance of $5 \AA$ is equal to a fiber period of the diene and diyne polymers. Therefore, the layered polymer crystals act as the template for the polymerization of 1,3-dienyl- and 1,3-diynylamines in the interlayer space. Consequently, the photopolymerization occurs in the side chain to give a new type of polymer crystals consisting of alternately stacked polymer nano-sheets, as shown in the supposed reaction profile for the polymerization of the dienyl and diynyl amines intercalated into PMA crystals (Figure 8). Similar alternatingly stacked polymer crystals have also been prepared from the corresponding monomer crystals containing both the diene and diyne moieties by simultaneous or stepwise topochemical polymerizations. Eventually, the photoreactivity of the unsaturated functional groups in the side chain is determined by the kind of unsaturated groups and the stacking distance of the amine molecules in the layers.

Acknowledgments. This work was supported by PRESTO-JST (Conversion and Control by Advanced Chemistry) and Grant-in-Aid for Science Research (B) (13450381) from the Ministry of Education, Culture, Sports, Science and Technology of Japan (MEXT). The authors acknowledge Dr. Kunio Oka, Osaka Prefecture University, for the $\gamma$-radiation experiments.

\section{REFERENCES}

1. Y. Chujo, Curr. Opin. Solid State Mater, 1, 806 (1996).

2. D. W. Bruce and D. O'Hare, Eds., "Inorganic Materials", 2nd ed, John Wiley \& Sons, Ltd., Chichester, 1996.

3. F. Schuth, K. S. W. Sing, and J. Weitkamp, Eds., "Handbook of Porous Solids", Wiley-VCH, Weinheim, 2002, vols 1-5.

4. M. S. Whittingham and A. J. Jacobsen, Eds., "Intercalation Chemistry", Academic Press, New York, N.Y., 1982.

5. J. L. Atwood, J. E. D. Davies, D. D. Macnicol, and F. Vögtle, Eds., "Comprehensive Supramolecular Chemistry, vol. 7, Solid-State Supramolecular Chemistry: Two- and Three-Dimensional Inorganic Networks", Pergamon, Oxford, 1996.
6. D. O'Hare, New J. Chem., 18, 989 (1994).

7. A. Okada and A. Usuki, Mater. Sci. Eng., C, 3, 109 (1995).

8. P. Judeinstein and C. Sanchez, J. Mater. Chem., 6, 511 (1996).

9. M. Ogawa and K. Kuroda, Bull. Chem. Soc. Jpn., 70, 2593 (1997).

10. T. E. Mallouk and J. A. Gavin, Acc. Chem. Res., 31, 209 (1998).

11. J. Kalousova, J. Votinsky, L. Benes, K. Melanova, and V. Zima, Collect. Czech. Chem. Commun., 63, 1 (1998).

12. A. Usuki, M. Kawasumi, Y. Kojima, Y. Fukushima, A. Okada, T. Kurauchi, and O. Kamigaito, J. Mater. Res., 8, 1179 (1993).

13. Y. Kojima, A. Usuki, M. Kawasumi, A. Okada, Y. Fukushima, T. Kurauchi, and O. Kamigaito, J. Mater. Res., 8, 1185 (1993).

14. M. Kawasumi, N. Hasegawa, M. Kato, A. Usuki, and A. Okada, Macromolecules, 30, 6333 (1997).

15. E. P. Giannelis, Adv. Mater, 8, 29 (1996).

16. A. W. Coleman, S. G. Bott, S. D. Morley, C. M. Means, K. D. Robinson, H. Zhang, and J. L. Atwood, Angew. Chem., Int. Ed. Engl., 27, 1361 (1988).

17. J. L. Atwood, F. Hamada, K. D. Robinson, G. W. Orr, and R. L. Vincent, Nature, 349, 683 (1991).

18. M. Miyata, M. Shibakami, S. Chirachanchai, K. Takemoto, N. Kasai, and K. Miki, Nature, 343, 446 (1990).

19. K. Biradha, D. Dennis, V. A. MacKinnon, C. V. K. Sharma, and M. J. Zaworotko, J. Am. Chem. Soc., 120, 11894 (1998).

20. K. T. Holman, A. M. Pivovar, J. A. Swift, and M. D. Ward, Acc. Chem. Res., 34, 107 (2001).

21. A. Matsumoto, T. Odani, K. Sada, M. Miyata, and K. Tashiro, Nature, 405, 328 (2000).

22. A. Matsumoto and T. Odani, Macromol. Rapid Commun., 22, 1195 (2001).

23. A. Matsumoto, S. Oshita, and D. Fujioka, J. Am. Chem. Soc., 124, 13749 (2002).

24. T. Odani and A. Matsumoto, Polym. J., 34, 841 (2002).

25. A. Matsumoto, K. Sada, K. Tashiro, M. Miyata, T. Tsubouchi, T. Tanaka, T. Odani, S. Nagahama, T. Tanaka, K. Inoue, S. Saragai, and S. Nakamoto, Angew. Chem., Int. Ed., 41, 2502 (2002).

26. S. Nagahama, K. Inoue, K. Sada, M. Miyata, and A. Matsumoto, Cryst. Growth Des., 3, 247 (2003).

27. V. Ramamurthy, Ed., "Photochemistry in Organized and Constrained Media", VCH Publishers, New York, N.Y., 1991.

28. T. Odani, A. Matsumoto, K. Sada, and M. Miyata, Chem. Commun., 2001, 2004.

29. D. F. O'Brien, B. Armitage, A. Benedicto, D. E. Nennett, H. G. Lamparski, Y. S. Lee, W. Srisiri, and T. M. Sisson, Acc. Chem. Res., 31, 861 (1998).

30. V. Enkelmann, Adv. Polym. Sci., 63, 91 (1984).

31. A. Matsumoto, Polym. J., 35, 93 (2003).

32. S. Okada, S. Peng, W. Spevak, and D. Charych, Acc. Chem. Res., 31, 229 (1998).

33. H. Zuilhof, H. M. Barentsen, M. van Dijk, E. J. R. Schdhölter, R. J. O. M. Hoofman, L. D. A. Siebbeles, M. P. de Haas, and J. M. Warman, in "Supramolecular Photosensitive and Electroactive Materials", H. S. Nalwa, Ed., Academic Press, San Diego, CA., 2001, chapt. 4, p 339.

34. A. Mueller and D. F. O’Brien, Chem. Rev., 102, 727 (2002).

35. A. Sarkar, S. Okada, H. Matsuzawa, H. Matsuda, and H. Nakanishi, J. Mater. Chem., 10, 819 (2000). 